\title{
Dissociation, memory commission errors, and heightened autonomic reactivity
}

Citation for published version (APA):

Giesbrecht, T. M., Geraerts, E. G., \& Merckelbach, H. L. G. J. (2007). Dissociation, memory commission errors, and heightened autonomic reactivity. Psychiatry Research, 150(3), 277-285.

https://doi.org/10.1016/j.psychres.2006.04.016

Document status and date:

Published: 01/01/2007

DOI:

10.1016/j.psychres.2006.04.016

Document Version:

Publisher's PDF, also known as Version of record

\section{Please check the document version of this publication:}

- A submitted manuscript is the version of the article upon submission and before peer-review. There can be important differences between the submitted version and the official published version of record.

People interested in the research are advised to contact the author for the final version of the publication, or visit the DOI to the publisher's website.

- The final author version and the galley proof are versions of the publication after peer review.

- The final published version features the final layout of the paper including the volume, issue and page numbers.

Link to publication

\footnotetext{
General rights rights.

- You may freely distribute the URL identifying the publication in the public portal. please follow below link for the End User Agreement:

www.umlib.nl/taverne-license

Take down policy

If you believe that this document breaches copyright please contact us at:

repository@maastrichtuniversity.nl

providing details and we will investigate your claim.
}

Copyright and moral rights for the publications made accessible in the public portal are retained by the authors and/or other copyright owners and it is a condition of accessing publications that users recognise and abide by the legal requirements associated with these

- Users may download and print one copy of any publication from the public portal for the purpose of private study or research.

- You may not further distribute the material or use it for any profit-making activity or commercial gain

If the publication is distributed under the terms of Article $25 \mathrm{fa}$ of the Dutch Copyright Act, indicated by the "Taverne" license above, 


\title{
Dissociation, memory commission errors, and heightened autonomic reactivity
}

\author{
Timo Giesbrecht *, Elke Geraerts, Harald Merckelbach \\ Department of Experimental Psychology, University of Maastricht, PO Box 616, 6200 MD, The Netherlands
}

Received 16 March 2005; received in revised form 7 October 2005; accepted 21 April 2006

\begin{abstract}
If dissociative symptoms are manifestations of a psychological defense mechanism, one would expect people who have such symptoms to react with lower levels of physiological arousal and with memory omissions to emotionally provocative material. The current study tested this assumption in a sample of undergraduates. Sixty-two undergraduate students viewed a highly emotional video fragment. Pearson's product-moment correlations were calculated between dissociation (as indexed by the Dissociative Experiences Scale, DES) and all dependent measures. High dissociators exhibited elevated skin conductance responses (SCRs) to the fragment. Memory for the video fragment was then tested. While omission errors were unrelated to dissociation, high dissociators exhibited a tendency to produce commission errors. This could not be explained by a reduced working memory capacity. However, fantasy proneness was found related to high dissociators' commission errors. Thus, it seems that a pattern of heightened emotional reactivity and commission errors is typical for people with elevated dissociation scores. This pattern is difficult to reconcile with the defensive function ascribed to dissociation.
\end{abstract}

(C) 2006 Elsevier Ireland Ltd. All rights reserved.

Keywords: Dissociation; Commission errors; Autonomic reactivity; Working memory

\section{Introduction}

According to Bernstein and Putnam (1986, p. 727), dissociation is "a lack of normal integration of thoughts, feelings, and experiences into the stream of consciousness and memory". Many authors believe that it "functions to fragmentize, derealize, and depersonalize traumatic experiences" (Markowitsch, 2003, p. S133). Dissociation can be conceptualized as forming a continuum that ranges

\footnotetext{
* Corresponding author. Tel.: +31 43388 2178; fax: +31 43388 4196.

E-mail address: T.Giesbrecht@psychology.unimaas.nl (T. Giesbrecht).
}

from the minor dissociation of everyday life to major forms of psychopathology (Fischer and Elnitsky, 1990). Historically, dissociation has been considered a defense mechanism that enables the individual to withdraw psychologically from the impact of overwhelming traumatic events (Gershuny and Thayer, 1999). This view dates back to the 19th century psychologist Pierre Janet (1894), who coined the term "dissociation" and emphasized its role as a defensive maneuver in response to psychological trauma. A habitual tendency to dissociate would, however, promote psychopathology (Hacking, 1995). Following this tradition, recent clinical literature emphasizes the causal relationship between dissociation and trauma (Irvin, 1998; Gershuny and Thayer, 1999; Gast et al., 2001). 
While the view that dissociation is caused by exposure to traumatic events is widely accepted, empirical studies providing unequivocal support for this causal direction are still lacking. For example, Zlotnick et al. (1996) found a correlation of 0.40 between dissociation, as measured with the Dissociative Experiences Scale, and their own Sexual Assault Questionnaire (SAQ). Yet, the authors admit that the validity and the reliability of the SAQ are unknown. Similarly, Nash et al. (1993) investigated the link between trauma and dissociation in a sample of 105 women. They found that participants with a self-reported history of sexual abuse endorsed significantly more dissociative symptoms compared with women without such a history. However, this connection disappeared when a measure of family pathology was entered as a covariate in the analysis. This suggests that the connection between trauma and dissociation might be less straightforward than is often thought. This point is emphasized by Mulder et al. (1998), who summarized their findings in a large community study $(n=1000)$ as follows:

Any causal influence of childhood sexual abuse on dissociation is likely to be indirect and mediated by more general linkages between childhood sexual abuse and risks of mental disorder. (p. 809)

Another study yielding problematic results for the trauma-dissociation hypothesis is that by Sanders and Giolas (1991). These authors found retrospective selfreports of traumatic experiences and dissociative symptoms to be modestly correlated in a sample of adolescent psychiatric patients. Curiously, when hospital records were scored by a "blind" rater for indications of trauma, a slightly negative correlation emerged between ratings of traumatic experiences based on hospital records and dissociation. This suggests that dissociation is related to retrospective self-reports of traumatic experiences, while being unrelated to more objective and specific indices of such experiences. Recently, Merckelbach and Jelicic (2004) offered an explanation for this phenomenon. In two samples of undergraduate students $(n=43$ and $n=127$ ), they found that dissociative experiences are related to the endorsement of vague, but not specific trauma items. This response tendency might also have played a role in other studies that found a link between dissociation and trauma as measured by retrospective selfreport scales of traumatic experiences.

Mild dissociative symptoms are rather common in the general population, with $80 \%$ to $90 \%$ of the respondents indicating that they sometimes experience these symptoms (Gershuny and Thayer, 1999). This is difficult to reconcile with the alleged traumatic etiology of dissociative symptoms, which implies that they should have a lower base rate. In addition, Lang et al. (1998) investigated the influence of heritability on dissociative experiences using a twin study. They report that about half of the variability in dissociative experiences can be attributed to heritability. The evidence concerning the genetic predisposition of dissociative experiences is, however, mixed, as another study (Waller and Ross, 1997) reports no genetic influence, while a recent study in children and adolescents lends support to the notion of a genetic predisposition of dissociation (Becker-Blease et al., 2004). Thus, the high prevalence and the possible heritable basis of dissociative phenomena make a direct causal link between dissociation and trauma less likely. It also underlines the importance of a different research perspective, namely one that focuses on the trait-like features of dissociation. One robust finding in this domain is that there exists a substantial overlap between dissociation and fantasy proneness (Rauschenberger and Lynn, 1995; Merckelbach et al., 2000; Waldo and Merritt, 2000). Fantasy proneness refers to a deep and extensive involvement in fantasizing and daydreaming (Merckelbach and Muris, 2001). While fantasy proneness is integral to healthy psychological functioning, an inability to control the cognitive processes implicated in imaginative involvement may be associated with psychopathology (Rauschenberger and Lynn, 1995). Fantasy proneness has repeatedly been shown to be related to dissociation in both clinical (Pekala et al., 1999-2000; Merckelbach et al., 2005) and non-clinical samples (Merckelbach et al., 1999, 2000) with correlations ranging from 0.41 (Pekala et al., 1999-2000) to 0.55 (Merckelbach et al., 2000).

Given the fact that fantasy proneness is associated with susceptibility to pseudo-memories, dissociation might also be related to a tendency to confabulate. Evidence for this comes from a study by Merckelbach et al. (2000). Participants watched 40 slides, with 20 depicting photographs of common objects or situations and the other 20 being a short paragraph describing a scene or situation. Following this, participants were given a surprise recognition test in which they had to identify slides they had seen earlier in a series of old and new slides. They also had to indicate whether they had seen the "old" slide as a photograph or a paragraph. Two types of errors may occur during this task. Participants may erroneously confuse a picture with a text or vice versa. This would be a reality-monitoring error. Participants might also claim that they recognize a slide, which was not presented earlier. This would be a pseudo-memory, i.e., a commission error. Dissociative experiences were found to be related to commission errors, but not to reality-monitoring errors. 
In a more recent study, Candel et al. (2003) examined memory-commission errors in a sample of undergraduate students scoring either high $(n=19)$ or low $(n=19)$ on the DES. The authors presented an emotional narrative to the participants, who then had to complete a free-recall task. Dissociation was associated with commission errors, but not with the proportion of correct recall, with high dissociators committing significantly more commission errors than low dissociators. In contrast to other studies (Merckelbach et al., 2000), the link between dissociation and commission errors was not mediated by fantasy proneness. This, however, might have been due to the limited sample size in the Candel et al. (2003) study.

Our study attempted to replicate the findings of Candel et al. (2003), but also tried to extend our understanding as to why commission errors are associated with heightened dissociation. One possibility is that this association has to do with high dissociators suffering from limited working memory capacity. A limited working memory capacity might hamper encoding, leading to gaps in memory (Brewin and Saunders, 2001), which are later filled in by participants, thereby leading to confabulations. Thus, the first issue examined in the current study is whether high dissociators' commission errors are related to working memory problems.

A second issue addressed by our study has to do with the defensive function that is often ascribed to dissociative experiences (Gershuny and Thayer, 1999). If this idea is correct, one would hypothesize that high dissociators show fewer hits on a memory task for emotional material (i.e., one would expect more omission errors), as one of the core features of dissociation is psychogenic amnesia (American Psychiatric Association, 1994). During exposure to the emotion-provoking material, one would also expect them to exhibit attenuated skin conductance responses as compared with low dissociators (e.g., Simeon, 2004). That is, one would predict that high dissociators could withdraw themselves psychologically from emotional events. Alternatively, if dissociative experiences and fantasy proneness described a common domain, high dissociators' skin conductance responses would be more pronounced as compared with those of low dissociators due to their more pronounced imaginative involvement in the emotional material (Candel and Merckelbach, 2003).

\section{Methods}

\subsection{Participants}

Participants were 62 undergraduate students enrolled at Maastricht University. Forty-five of them were women.
Their mean age was 19.03 years (S.D. $=1.56$, range $=17$ to 26 years). Participants were compensated through course credit points and gave written consent prior to taking part. The study was approved by the local ethical committee.

\subsection{Psychometric instruments}

\subsubsection{Dissociative Experiences Scale (DES; Cronbach's $\alpha=0.92$ )}

The DES (Bernstein and Putnam, 1986) is a self-report scale asking respondents to indicate on $100-\mathrm{mm}$ visual analogue scales to what extent they experience 28 dissociative phenomena in daily life. Examples of such phenomena include feelings of depersonalization, derealization, and psychogenic amnesia. The DES has high internal consistency and test-retest correlations ranging from 0.74 to 0.84 . In a meta-analytic study, Van Ijzendoorn and Schuengel (1996) provide evidence for the sound psychometric properties of the DES. We chose not to calculate the Dissociative Experiences Scale Taxon (DEST; Waller et al., 1996), as recent research casts doubts on its stability in non-clinical samples (Watson, 2003a) and its accuracy in identifying pathological dissociation (Modestin and Erni, 2004).

\subsubsection{Creative Experiences Questionnaire (CEQ; Cronbach's $\alpha=0.70$ )}

The CEQ (Merckelbach et al., 2001) is a 25-item selfreport measure of fantasy proneness scaled in the true/ false form. It requires respondents to specify whether they exhibit various characteristics of fantasy proneness (e.g., "As a child, I thought that the dolls, teddy bears, and stuffed animals that I played with were living creatures" and "When I think of something cold, I actually get cold"). A total score is obtained by summing all yes answers. Merckelbach et al. (2001) reported adequate test-retest stability, internal consistency, and concurrent validity for this instrument.

\subsubsection{Digit span forward and backward}

The digit span forward is a standard measure of working memory capacity (Lezak et al., 2004). A sequence of digits ranging from 1 to 9 of increasing length is presented to the participant who attempts to repeat it immediately. The number of digits in the longest sequence that has been repeated correctly is taken as the person's score. When the participant fails to recall two sequences of the same length, the test is terminated. Digit span backward is similar to the digit span forward, except that the participant has to recall the digits in reversed order. 


\subsection{Psychophysiological measures}

In the present study, one 3-min episode of skin conductance was sampled at $40 \mathrm{~Hz}$. While we recognize the limitations of only one physiological measure, we chose to measure skin conductance responses for two reasons: (1) Skin is a reliable indicator of sympathetic nervous system activity that can be measured unobtrusively (Kring and Gordon, 1998). (2) There is there exists an extensive literature indicating that skin conductance is proportional to the emotionality of stimuli (Fowles, 1980). Skin conductance was measured with two silver/ silver chloride $(\mathrm{Ag} / \mathrm{AgCl})$ electrodes filled with isotonic electrode gel and placed on the thenar and hypothenar eminences of the palm of the non-dominant hand. Before placement of the electrodes, participants rinsed their hands with distilled water. Respiration rate was measured with a strain gauge around the participant's waist. Respiration was recorded as control variable so as to make sure that skin conductance was related to the film fragment and not to respiratory irregularities. A personal computer was used for stimulus presentation, while a second personal computer running Psylab 7 (Dow, 1997) was used for on-line storage of skin conductance response and respiration data. Stimuli were presented on a 19-in. color monitor. The timing of the video fragment and the skin conductance measure was synchronized.

\subsection{Stimulus material}

A highly emotional video fragment from the Hollywood film American History X (Kaye, 1998) was used. The fragment lasted approximately $2 \mathrm{~min}$ and depicted a neo-Nazi attacking a group of three AfricanAmericans who try to steal his car. First, he shoots at them, ultimately forcing one of them to put his teeth on the sidewalk in order to step on his head. We selected this particular video fragment because previous work in our laboratory (Smeets et al., 2004) made clear that participants evaluated it as emotionally provocative and that the video fragment led to an increase in both anxiety and tension. In more general terms, research (e.g., Jansen and Frijda, 1994) shows that video clips may elicit strong emotional arousal in participants.

\subsection{Procedure}

Participants were tested individually in our laboratory with a female experimenter present. First, the DES and the CEQ were administered. Next, participants completed the digit span forward and backward. Then, participants were connected to the psychophysiological recording equipment and given $5 \mathrm{~min}$ to accommodate. Following this, they were instructed to watch the video fragment. At the end of it, the experimenter asked them to write down everything they could remember from the fragment. Participants were given sufficient time to complete this task. When the participants had completed the task, they were thanked for their participation and fully debriefed.

\subsection{Statistical analyses}

Statistical analyses were performed using SPSS software. Cronbach's $\alpha$ values were used to estimate the DES's and CEV's internal consistency.

Two independent raters, who were blind to the DES and CEQ scores of participants, evaluated free-recall performance (hits) using a set of 31 predefined criteria (Smeets et al., 2004). The same raters identified commission errors in participants' free-recall protocols. Commission errors were defined as details mentioned by the participant, which were clearly not present in the video fragment (e.g., 'The African-American man shoots back at the Neo-Nazi.'). Both hits and commission errors were averaged across raters.

Participants' skin conductance response (SCR) to exposure to the video fragment was measured in the 4-s window after the most emotional moment of the video clip. This moment lasted about 1-s and depicted a neoNazi kicking the head of an African-American who is lying with his teeth on the sidewalk (i.e., Californian curve kick). We selected this event because free-recall transcripts collected during earlier experiments in our laboratory showed that it is experienced as an emotionally provocative fragment (see Smeets et al., 2004). SCR was defined as any deflection relative to baseline (measured during the 8-s preceding the onset of the film fragment; Lundgren et al., 2004) exceeding $0.05 \mu \mathrm{S}$ (micro-siemens). To normalize the distribution, SCR data were square-roottransformed.

To explore the possibility that dissociators exhibited a pattern in which heightened SC reactivity was followed by a steep decrease in reactivity (i.e., reflecting defensive processes), we examined the time course of SC during an 8-s window following the maximum SCR described above and calculated the decrement in SC during this period relative to the maximum SCR.

Pearson's product-moment correlations were calculated between the DES and all dependent measures. The mediational effect of fantasy proneness was investigated using the approach outlined in Baron and Kenny (1986). 


\section{Results}

\subsection{Psychometric instruments}

\subsubsection{Individual differences measures}

Mean DES and CEQ scores were 17.86 (S.D.= 10.46) and 7.22 (S.D.=3.73), respectively. These scores correspond with values that previous studies reported for student samples (Merckelbach et al., 2002). Table 1 presents Pearson's product-moment correlations between the DES, the CEQ, and performance on the digit span task.

As can be seen, there was a significant correlation between DES and CEQ scores. Thus, participants who reported more dissociative experiences exhibited stronger tendencies to fantasize.

\subsubsection{Digit Span}

Digit span forward and backward scores were 6.18 $($ S.D. $=1.11)$ and 4.65 (S.D. = 1.10), respectively. Correlations between digit span forward, backward, and dissociative experiences remained non-significant.

\subsection{Recall performance}

\subsubsection{Free recall}

Inter-rater reliability values for hits and commissions were 0.85 and 0.82 , respectively. Participants recalled on average $36 \%$ (S.D. $=8 \%$ ) of the critical details, while making on average 0.37 (S.D. $=0.58)$ commission errors (in absolute numbers). Pearson's product-moment correlations showed that both individual differences in dissociative experiences and fantasy proneness were positively related to commission errors, while not affecting hits (see Table 1). It is worth noting that previous research (Smeets

Table 1

Pearson's product-moment correlations between dissociative experiences (DES), fantasy proneness (CEQ), digit span, free-recall performance, and commission errors for an undergraduate sample $(n=62)$

\begin{tabular}{llcc}
\hline & & \multicolumn{2}{c}{$\begin{array}{c}\text { Individual } \\
\text { difference } \\
\text { measures }\end{array}$} \\
\cline { 3 - 4 } & & DES & CEQ \\
\hline Individual difference & DES & - & $0.51^{*}$ \\
measures & CEQ & $0.51^{*}$ & - \\
Digit span & Forward & -0.11 & 0.10 \\
Free recall & Backward & 0.15 & 0.11 \\
& Proportion hits & -0.07 & -0.06 \\
& Commission errors & $0.34^{*}$ & $0.36^{*}$ \\
\hline
\end{tabular}

Only relevant correlations are shown.

* Correlation is significant at the 0.01 level (2-tailed). et al., 2004) in our laboratory indicates that recall or emotional impact is unaffected by whether participants are familiar with the video fragment.

One might wonder whether the finding that dissociation and fantasy proneness are related to the number of commission errors in memory is confounded by the selfpaced nature of our free-recall task. The length of a written report might exert a strong influence on the reported content. That is why we calculated Pearson's correlations between the number of words in the written report and the number of hits and commission errors. As expected, the number of hits was positively related to the number of words $(r=0.64, P<0.01)$; however, more interestingly, commission errors were unrelated to the number of words $(r=-0.03, P>0.05)$. Therefore, our finding that heightened levels of dissociation and fantasy proneness were related to commission errors in memory is not dependent on the length of the report participants give.

\subsubsection{Modeling fantasy proneness as mediator during free recall}

The mediational effect of fantasy proneness on the relationship between dissociation and commission errors during the free-recall task was examined following the approach recommended by Baron and Kenny (1986). Firstly, we tested the unmediated model, consisting of the link between dissociation and commission errors in memory without controlling for fantasy proneness. Dissociative experiences, as measured by the DES, were found to predict commission errors during the free-recall task, $B=0.02, \beta=0.34, t(61)=2.78, P<0.01$.

Next, the mediated model was tested. This model consisted of dissociative tendencies, fantasy proneness, and commission errors during the free-recall task. Dissociative tendencies predicted fantasy proneness, $B=0.18, \beta=0.51, t(61)=4.60, P<0.01$, whereas a trend emerged for fantasy proneness to predict a tendency to commit memory commission errors, $B=0.04, \beta=0.25$, $t(61)=21.14, P=0.07$. In addition, the effect of dissociation on memory commission errors decreased and was no longer significant, $B=0.01, \beta=0.21, t(61)=1.51$, $P=0.14$. However, as it is not sufficient to show that the link between the independent variable and the dependent variable becomes non-significant when the mediator is added to the model (Frazier et al., 2004), we calculated Sobel's (1982) test. This test indicates whether the indirect influence of the independent variable via the mediator is different from zero. Only a trend emerged, $z=1.69, P=0.09$, with $38 \%$ of the relation between dissociation and commission errors in free-recall task being mediated by fantasy proneness. 


\subsection{Skin conductance}

Dissociative experiences were positively correlated with SCR magnitude: $r=0.34, P=0.01$, whereas correlations between dissociative experiences and SC baseline level remained non-significant $(r=-0.15$, $P>0.10)$. Fantasy proneness was not related to SCR magnitude $(r=0.18, P>0.10)$.

Dissociation was unrelated to the SC decrement following the maximum SCR $(r=0.03, P>0.10)$. While there is no reason to expect that the 4-s window described above should differentially affect high and low dissociators, we excluded this possibility by calculating the maximum SCR during the whole video fragment. This approach did not alter the correlation between dissociation and the SCR $(r=0.34, P<0.01)$.

\section{Discussion}

The most important findings of the current study can be catalogued as follows. To begin with, heightened dissociation was related to commission errors during the free-recall task. Dissociation was, however, completely unrelated to the proportion of hits (i.e., accurate information elements). Secondly, in contrast to Candel et al. (2003), a mediator analysis revealed a trend for the link between commission errors and dissociation to be partially mediated by fantasy proneness during free recall. Thirdly, our findings cannot be explained by individual differences in working memory capacity, as all correlations with dissociation and working memory remained non-significant. Fourthly, dissociative tendencies were accompanied by a higher SCR to the emotional video.

Our finding that high dissociators do not perform worse on an explicit memory task is in line with Sandberg et al. (2001), who reported that high dissociators do not exhibit degraded recall of danger cues from a video fragment. Our results are also in line with those of Brewin and Saunders (2001), who found that artificially inducing dissociation by means of a dual task during exposure to a video fragment does not lead to deterioration of recall performance. However, while these two previous studies clearly show that dissociation is unrelated to recall performance in terms of hits, both failed to look at commission errors. So far, only Candel et al. (2003) looked at whether dissociation was linked to the fabrication of details that were not present in the stimulus material (i.e., commission errors). In line with the aforementioned studies, these authors noted that the tendency to dissociate was unrelated to free-recall performance in terms of hits. Yet, Candel et al. (2003) did find evidence that dissociation was linked to commission errors in free recall. They then explored whether the relationship between dissociative experiences and commission errors might be modulated by fantasy proneness. Candel et al. (2003) found no evidence for such a mediating role of fantasy proneness. Replicating the results of Candel et al. (2003), our study showed that dissociation was linked to commission errors. While in the clinical literature, dissociation is rarely linked to confabulatory tendencies (but see Hyman and Billings, 1998; Candel et al., 2003), the present finding reminds us of the historical roots of the concept of dissociation, which lie in the syndrome of hysteria (Kihlstrom, 1994). Interestingly, hysterics were renowned for their tendency to verbally exaggerate and for being fantasy ridden (e.g., Chodoff, 1974). In line with this assertion and unlike the study of Candel et al., we found some indications that fantasy proneness might partially mediate the dissociation-memory commission link. That Candel et al. (2003) were unable to detect this mediational role of fantasy proneness may have to do with two features of their study. One is that their sample was relatively small and consisted of students selected for their low and high DES scores. Another feature that might have obscured the role of fantasy proneness is the type of stimulus material employed by Candel et al. (2003). These authors exposed their participants to an emotional narrative that was read aloud. Because material was presented only in the auditory modality, participants might have had the opportunity to fully concentrate on the material, which in turn might have limited the room for commission errors. Relying on a highly emotional video clip, our stimulus material was more ecologically valid and may have allowed for a stronger influence of fantasy proneness on commission errors in memory. However, while this finding offers an explanation for high dissociators' susceptibility to pseudo-memories (Hyman and Billings, 1998; Candel et al., 2003), it has to be interpreted with caution, as only a trend emerged regarding the mediating influence of fantasy proneness.

We found no evidence that working memory capacity is related to dissociation. This concurs with the fact that dissociation was not correlated with memory performance in terms of hits. Again, however, our failure to find a connection between dissociation and a traditional measure of short-term memory has to be interpreted with caution. A clinical study by Cima et al. (2001) showed that cognitive differences between forensic patients high and low on dissociation might be connected to deficits in executive functioning. In addition, in one of our own studies (Giesbrecht et al., 2004), we found that 
dissociation was related to minor disruptions in executive functioning.

In the current study, higher dissociation scores were accompanied by a more pronounced SCR to the critical scene of the emotional video fragment. Importantly, this pronounced SCR response was not followed by a dissociative or defensive process, which might serve to counter regulate this increased arousal. Our SC findings are difficult to reconcile with the view that dissociative experiences constitute a defense mechanism that allows an individual to psychologically withdraw from the impact of the situation. Such a mechanism should reduce emotional engagement, thereby leading to lowered SCRs. However, while SC is a reliable and valid measure of emotionality (Fowles, 1980), future research relying on heart rate might further broaden our understanding of the supposedly defensive properties of dissociation. Heart rate is a valid measure of defensive responding. More specifically, defensive reactions are associated with heartrate acceleration (e.g., Verschuere et al., 2004). In addition, our study only measured dissociation as a trait, which means that our data do not provide any information about the current dissocialized state of our participants during the experimental condition. Therefore, future studies should also quantify state (i.e., peritraumatic) dissociation and its relation to both physiological responsiveness and commission errors in memory during emotional events in the laboratory.

If dissociation were to serve a defensive function, one would also predict higher dissociation scores to be accompanied by higher rates of forgetting. But, as indicated before, dissociation was not negatively related to hit rates (i.e., the inverse of forgetting). Other attempts to document a relationship between dissociation and defensive forgetting were also unsuccessful (e.g., Sandberg et al., 2001). One of the few studies that reported evidence that might be interpreted as support for the defensive function of dissociation was that by Koopman et al. (2004). These researchers found dissociative experiences to be associated with lowered mean heart rate in a sample of 41 delinquents. But then the question arises whether this lowered mean heart rate reflects defensive blunting or a general deficit in arousal (see also Griffin et al., 1997). Clearly, the psychophysiology of dissociation is an under-researched area and future studies addressing how tonic and phasic arousal relate to dissociation would be welcome.

Based on our findings, we would argue that dissociative experiences, at least in our sample of undergraduate students, probably do not serve any defensive function. Watson $(2001,2003 \mathrm{~b})$ pointed out that there is one alternative possibility that deserves serious consid- eration: that individual differences in sleeping behavior underlie variations in dissociative experiences (Watson, 2001, 2003b; Giesbrecht and Merckelbach, 2004). The idea here is that high dissociators might more readily pass from normal waking into dream-like states, resulting in dissociative episodes and fantasy proneness. This idea is based on correlational studies showing robust associations between dissociation (as measured by the DES) and sleep experiences (as indexed with the Iowa Sleep Experiences Survey; ISES; Watson, 2001, 2003b) ranging from 0.37 (Giesbrecht and Merckelbach, 2004) to 0.54 (Watson, 2001). Positive response tendencies can be ruled out as a primary source of the connection between disturbed sleep patterns and dissociation (Giesbrecht and Merckelbach, 2004). This connection, however, does not necessarily imply that traumatic experiences have no role in the development of dissociative symptoms. For example, Harvey et al. (2003) consider sleep disruptions a typical reaction to traumatic events. Other factors, such as genetic predisposition (e.g., Lang et al., 1998), may further contribute to the sleepdissociation link. Again, studies on the psychophysiology of dissociative experiences could shed more light on this issue. Thus, it would be interesting to measure background EEG in people high or low on dissociation. If high dissociators would exhibit typical sleep features in their waking EEG, this would constitute compelling evidence for a sleep-dissociation link (Watson, 2001; Giesbrecht and Merckelbach, 2004).

To conclude, our findings are difficult to reconcile with the idea that dissociative experiences are manifestations of a defense mechanism, at least in our sample of undergraduate students. Plainly, new approaches to the study of dissociative experiences are needed. One promising avenue is the link between dissociative experiences and sleep disruptions. Studying differences in information processing and executive functioning between high and low dissociators might also broaden our understanding. However, in contrast to previous studies (e.g., Sandberg et al., 2001), researchers should not limit their variables of interest to measures of hits, but should also take memory commissions into account. A combination of these approaches might contribute to a better understanding of the etiology of dissociative experiences.

\section{Acknowledgements}

This study was supported by a grant from the Dutch organisation for scientific research N.W.O., Grant No. 402-01-088-D. We thank Bob Wilkinson for his helpful comment on an early version of this article. 


\section{References}

American Psychiatric Association, 1994. Diagnostic and Statistical Manual of Mental Disorders, 4th ed. APA, Washington, DC.

Baron, R., Kenny, D., 1986. The moderator-mediator variable distinction in social psychological research: conceptual, strategic, and statistical considerations. Journal of Personality and Social Psychology 51, 1173-1182.

Becker-Blease, K.A., Deater-Deckard, K., Eley, T., Freyd, J.J., Stevenson, J., Plomin, R., 2004. A genetic analysis of individual differences in dissociative behaviors in childhood and adolescence. Journal of Child Psychology and Psychiatry and Allied Disciplines 45, 522-532.

Bernstein, E.M., Putnam, F.W., 1986. Development, reliability, and validity of a dissociation scale. Journal of Nervous and Mental Disease 174, 727-735.

Brewin, C.R., Saunders, J., 2001. The effect of dissociation at encoding on intrusive memories for a stressful film. British Journal of Medical Psychology 74, 467-472.

Candel, I., Merckelbach, H., 2003. Fantasy proneness and thought suppression as predictors of the medical student syndrome. Personality and Individual Differences 35, 519-524.

Candel, I., Merckelbach, H., Kuijpers, M., 2003. Dissociative experiences are related to commissions in emotional memory. Behaviour Research and Therapy 41, 719-725.

Chodoff, P., 1974. The diagnosis of hysteria: an overview. American Journal of Psychiatry 131, 1073-1078.

Cima, M., Merckelbach, H., Klein, B., Schellbach-Matties, R., Kremer, K., 2001. Frontal lobe dysfunctions, dissociation, and trauma self-reports in forensic psychiatric patients. Journal of Nervous and Mental Disease 189, 188-190.

Dow, R., 1997. Psylab (Version 7). Contact Precision Instruments, London.

Fischer, D.G., Elnitsky, S., 1990. A factor analytic study of two scales measuring dissociation. American Journal of Clinical Hypnosis 32, 201-207.

Fowles, D.C., 1980. The three arousal model: implications of Gray's two-factor learning theory for heart rate, electrodermal activity, and psychopathy. Psychophysiology 17, 87-104.

Frazier, P.A., Tix, A.P., Barron, K.E., 2004. Testing moderator and mediator effects in counseling psychology research. Journal of Counseling Psychology 51, 115-134.

Gast, U., Rodewald, F., Nickel, V., Emrich, H.M., 2001. Prevalence of dissociative disorders among psychiatric inpatients in a German university clinic. Journal of Nervous and Mental Disease 189, 249-257.

Gershuny, B.S., Thayer, J.F., 1999. Relations among psychological trauma, dissociative phenomena, and trauma-related distress: a review and integration. Clinical Psychology Review 19, 631-637.

Giesbrecht, T., Merckelbach, H., 2004. Subjective sleep experiences are related to dissociation. Personality and Individual Differences 37, 1341-1345.

Giesbrecht, T., Merckelbach, H., Geraerts, E., Smeets, E., 2004. Disruptions in executive functioning and dissociation in undergraduate students. Journal of Nervous and Mental Disease 192, 567-569.

Griffin, M.G., Resick, P.A., Mechanic, M.B., 1997. Objective assessment of peritraumatic dissociation: psychophysiological indicators. American Journal of Psychiatry 154, 1081-1088.

Hacking, I., 1995. Rewriting the Soul: Multiple Personality and the Sciences. Princeton University Press, Princeton, NJ.

Harvey, A.G., Jones, C., Schmidt, D.A., 2003. Sleep and posttraumatic stress disorder: a review. Clinical Psychology Review 23, 377-407.
Hyman Jr., I.E., Billings, F.J., 1998. Individual differences and the creation of false childhood memories. Memory 6, 1-20.

Irvin, H.J., 1998. Dissociative tendencies and the sitting duck: are selfreports of dissociation and victimization symptomatic of neuroticism? Journal of Clinical Psychology 54, 1005-1015.

Janet, P., 1894. L'Automatisme Psychologique. Societe Pierre Janet, Paris.

Jansen, D.M., Frijda, N.H., 1994. Modulation of acoustic startle response by film-induced fear and sexual arousal. Psychophysiology 31, 565-571.

Kaye, T., 1998. American History X. New Line Cinema, Los Angeles.

Kihlstrom, J.F., 1994. One hundred years of hysteria. In: Lynn, S.J., Rhue, J. (Eds.), Dissociation: Clinical and Theoretical Perspective. Guildford Press, New York, pp. 363-394.

Koopman, C., Carrison, V., Butler, L.D., Sudhakar, S., Palmer, L., Steiner, H., 2004. Relationships of dissociation and childhood abuse and neglect with heart rate in delinquent adolescents. Journal of Traumatic Stress 17, 47-54.

Kring, A.M., Gordon, A.H., 1998. Sex differences in emotion: expression, experience, and physiology. Journal of Personality and Social Psychology 74, 686-703

Lang, K.L., Paris, J., Zweig-Frank, H., Livesley, W.J., 1998. Twin study of dissociative experiences. Journal of Abnormal Psychology $186,345-351$.

Lezak, M.D., Howieson, D.B., Loring, D.W., 2004. Neuropsychological Assessment. Oxford University Press, Oxford.

Lundgren, J., Berggren, U., Carlsson, S.G., 2004. Psychophysiological reactions in dental phobic patients with direct vs. indirect fear acquisition. Journal of Behavior Therapy and Experimental Psychiatry $35,3-12$.

Markowitsch, H.J., 2003. Psychogenic amnesia. NeuroImage 20, S132-S138.

Merckelbach, H., Jelicic, M., 2004. Dissociative symptoms are related to endorsement of vague trauma items. Comprehensive Psychiatry $45,70-75$.

Merckelbach, H., Muris, P., 2001. The causal link between selfreported trauma and dissociation: a critical review. Behaviour Research and Therapy 39, 245-254.

Merckelbach, H., Muris, P., Rassin, E., 1999. Fantasy proneness and cognitive failures as correlates of dissociative experiences. Personality and Individual Differences 26, 961-967.

Merckelbach, H., Muris, P., Horselenberg, R., Stougie, S., 2000. Dissociative experiences, response bias, and fantasy proneness in college students. Personality and Individual Differences 28, 49-58.

Merckelbach, H., Horselenberg, R., Muris, P., 2001. The Creative Experiences Questionnaire (CEQ): a brief self-report measure of fantasy proneness. Personality and Individual Differences 31, 987-995.

Merckelbach, H., Horselenberg, R., Schmidt, H., 2002. Modeling the connection between self-reported trauma and dissociation in a student sample. Personality and Individual Differences 32, 695-705.

Merckelbach, H., à Campo, J., Hardy, S., Giesbrecht, T., 2005. Dissociation and fantasy proneness in psychiatric patients: a preliminary study. Comprehensive Psychiatry 16, 181-185.

Modestin, J., Erni, T., 2004. Testing the dissociative taxon. Psychiatry Research 126, 77-82.

Mulder, R.T., Beautrais, A.L., Joyce, P.R., Fergusson, D.M., 1998. Relationship between dissociation, childhood sexual abuse, and mental illness in a general population sample. American Journal of Psychiatry $155,806-811$. 
Nash, M.R., Hulsey, T.L., Sexton, M.C., Harralson, T.L., Lambert, W., 1993. Long-term sequelae of childhood sexual abuse: perceived family environment, psychopathology, and dissociation. Journal of Consulting and Clinical Psychology 61, 276-283.

Pekala, R., Kumar, V.K., Ainslie, V.K., Elliott, N.C., Mullen, K.J., Saninger, M.M, Masten, E., 1999-2000. Dissociation as a function of child abuse and fantasy proneness in a substance abuse population. Imagination, Cognition and Personality 19, 105-129.

Rauschenberger, S.L., Lynn, S.J., 1995. Fantasy proneness, DSM-IIIR Axis I psychopathology and dissociation. Journal of Abnormal Psychology 104, 373-380.

Sandberg, D.A., Lynn, S.J., Matorin, A.I., 2001. Information processing of an acquaintance rape scenario among high- and low-dissociating college women. Journal of Traumatic Stress 14, 585-603.

Sanders, B., Giolas, M.H., 1991. Dissociation and childhood trauma in psychological disturbed adolescents. American Journal of Psychiatry $148,50-54$.

Simeon, D., 2004. Depersonalisation disorder: a contemporary overview. CNS Drugs 18, 343-354.

Smeets, T., Candel, I., Merckelbach, H., 2004. Accuracy, completeness, and consistency of emotional memories. American Journal of Psychology 117, 595-609.

Sobel, M.E., 1982. Asymptotic confidence intervals for indirect effect instructural equation models. In: Leinhart, S. (Ed.), Sociological Models. Jossey-Bass, San Francisco, pp. 290-312.

van Ijzendoorn, M.H., Schuengel, C., 1996. The measurement of dissociation in normal and clinical populations: meta-analytic validation of the Dissociative Experience Scale (DES). Clinical Psychology Review 16, 365-382.
Verschuere, B., Crombez, G., Clercq, A., de Ernst, H.W., 2004. Autonomic and behavioral responding to concealed information: differentiating orienting and defensive responses. Psychophysiology 41, 461-466.

Waldo, T.G., Merritt, R.D., 2000. Family proneness, dissociaton, and DSM-IV Axis II symptomatology. Journal of Abnormal Psychology $109,555-558$.

Waller, N.G., Ross, C.A., 1997. The prevalence and biometric structure of pathological dissociation in the general population: taxometric and behavior genetic findings. Journal of Abnormal Psychology 106, 499-510.

Waller, N.G., Putnam, F.W., Carlson, E.B., 1996. Types of dissociation and dissociative types: a taxometric analysis of dissociative experiences. Psychological Methods 1, 300-321.

Watson, D., 2001. Dissociation of the night: individual differences in sleep-related experiences and their relation to dissociation and schizotypy. Journal of Abnormal Psychology 110, 526-535.

Watson, D., 2003a. Investigating the construct validity of the dissociative taxon: stability analysis of normal and pathological dissociation. Journal of Abnormal Psychology 112, 298-305.

Watson, D., 2003b. To dream, perchance to remember: individual differences in dream recall. Personality and Individual Differences 34, 1271-1286.

Zlotnick, C., Shea, M.T., Pearlstein, T., Simpson, E., Costello, E., Begin, A., 1996. The relationship between dissociative symptoms, alexithymia, impulsivity, sexual abuse, and self-mutilation. Comprehensive Psychiatry 37, 12-16. 